\begin{tabular}{|l|l|l|}
\hline \multicolumn{2}{|c|}{ PublisherInfo } \\
\hline \hline PublisherName & $:$ & BioMed Central \\
\hline \hline PublisherLocation & $:$ & London \\
\hline \hline PublisherImprintName & $:$ & BioMed Central \\
\hline \hline
\end{tabular}

\title{
Role of the mitotic checkpoint in transformation of Brca2 null cells
}

\begin{tabular}{|l|l|l||}
\hline \multicolumn{2}{|c||}{ ArticleInfo } \\
\hline \hline ArticleID & $:$ & 3628 \\
\hline \hline ArticleDOI & $:$ & $10.1186 /$ bcr-1999-66606 \\
\hline \hline ArticleCitationID & $:$ & 66606 \\
\hline \hline ArticleSequenceNumber & $:$ & 48 \\
\hline \hline ArticleCategory & $:$ & Paper Report \\
\hline \hline ArticleFirstPage & $:$ & 1 \\
\hline \hline ArticleLastPage & $:$ & 4 \\
\hline \hline & & RegistrationDate : 1999-8-19 \\
\hline ArticleHistory & $:$ & OnlineDate \\
\hline ArticleCopyright & $:$ & Current Science Ltd1999-8-19 \\
\hline \hline ArticleGrants & $:$ & \\
\hline \hline ArticleContext & $:$ & 1305811 \\
\hline \hline
\end{tabular}




\section{Keywords}

Brca2, p53, Bub1, Mad3L, mitotic checkpoint, proliferation, lymphoma

\section{Introduction}

$\mathrm{Brca} 2$ is a tumour suppressor gene involved in some hereditary human breast cancers. The murine gene encodes a nuclear protein that binds to Rad51, implicating BRCA2 in DNA repair. Mice homozygous for truncated $\mathrm{Brca} 2$ are mostly nonviable; however, the few that do survive show severe growth retardation and develop thymic lymphomas. The murine embryonic cells homozygous for truncated Brca2show a severe proliferative defect and are more susceptible to X-rays and other genotoxins, despite normal enforcement of checkpoints activated by DNA damage.

\section{Aims}

To determine the nature of proliferative arrest seen in cells with Brca2disruption and to try to explain how cells with a proliferative defect manage to escape its effects and form tumours in the thymus. Specifically, the roles of p53 or related molecules and the spindle assembly checkpoint were examined.

\section{Comments}

This is a detailed examination of important mitotic control pathways in a model of predisposition to neoplasia mediated by aberrant Brca2. Collaborative genes implicated here may play a role in human breast disease and the potential interplay between p53 and the spindle assembly checkpoint machinery via $B u b 1$ and/or Mad $3 L$ is intriguing. The novel p53 mutation shown may have implications for p53 functional studies, and the chromosomal instability demonstrated suggests that different checkpoint mutations influence the structural changes in the unstable genome.

\section{Methods}


Lymphomas and murine embryonic fibroblasts (MEFs) from mice homozygous for a Brca2 gene that encodes a protein with truncation at residue 1492 were studied extensively, together with relevant controls. Retroviral transduction was used to transfer expression constructs, consisting of mutant p53 linked to a green fluorescent protein reporter gene, into MEFs. Similar constructs were used for a dominant-negative mutation of the murine $B u b l$ gene.Flow cytometry was used to examine the cell cycle in MEFs following exposure to measured doses of X-rays. cDNAs encoding $p 53, B u b 1$, and $\operatorname{Mad} 3 L$ were cloned from thymic lymphomas and sequenced. Mutations were confirmed in genomic DNA and a full-length cDNA of mutant p53was cloned into an expression vector. Metaphase spreads were scored for structural and numerical abnormalities. Immunofluorescent staining was examined by confocal microscopy to detect unattached kinetochores stained with 3F3/2 monoclonal antibody, following treatment with spindle inhibitors.

\section{Results}

Unless otherwise stated the MEFs and lymphomas described here are from mice homozygous for a truncation in Brca2. MEFs exhibited growth retardation compared to MEFs isolated from wild-type embryos. This was reversed by the expression of either of two dominant-negative p53 mutants. Furthermore, expression of mutant $p 53$ transformed MEFs and they continued to grow for a prolonged period, in contrast to control or wild-type MEFs. Growth arrest was abrogated and MEFs expressing mutant $p 53$ continued to enter S-phase when exposed to gamma radiation. These results were confirmed using a temperature sensitive $p 53$ mutation.

Lymphoma cells failed to undergo growth arrest when exposed to gamma radiation, indicating loss of p53 checkpoints. Overexpression of wild-type $p 53$ in these cells decreases proliferation.

Three of four lymphomas tested had a novel mutation in $p 53$, resulting in in-frame deletion in codons 140-148 of exon5, with the same ability to reverse growth arrest.

Cell cycle checkpoints operating in G2/M and activated by spindle inhibitors were not grossly affected in the MEFs by truncation of Brca2 alone; however, the expression of mutant $p 53$ in MEFs led to loss of the gamma radiation induced G2/M checkpoint. The Brca2 null lymphoma cells also showed loss of gamma radiation induced mitotic checkpoints. Hence disruption of the mitotic checkpoint is a possible sequela of the p53 mutation found in the Brca2 null thymic lymphomas.

\section{Discussion}

Other genes known to be involved in the mitotic checkpoints were examined. Expression of a dominant-negative mutant version of Bub1 also reversed the growth arrest seen in BRCA2-deficient MEFs and led to transformation. When treated with spindle inhibitors, these cells were less able to undergo mitotic arrest and become polyploid. Three of four lymphomas harboured an insertion mutation of Bubl at residue 290, in a conserved domain for kinetochore localization and, in addition, one 
lymphoma was heterozygous for a mutant allele of Mad3L. That the Bub1 mutation is identical in all 4 independent thymic lymphomas is very unsusal. A dysfunctional spindle assembly checkpoint was further demonstrated in the lymphomas.

Aneuploidy was a consistent feature of MEFs expressing mutant $p 53$ or $B u b 1$; however, the patterns of structural aberrations differed between the two $p 53$ mutants.

\section{Additional information}

These results demonstrate that the defect in proliferation found in MEFs from mice with truncated Brca 2 is the result of active mitotic checkpoints involving $p 53$. Inactivating mutations in $p 53$ co-operate with Brca2 deficiency to enhance neoplastic tranformation of MEFs and this is corroborated by the mutation of $p 53$ in lymphomas in Brca 2 disrupted mice. Indeed $p 53$ inactivation by a trans-dominant mutation would seem to be essential for continued proliferation of Brca2 truncated lymphomas.

The checkpoint response to spindle inhibitors is lost only in lymphomas or when MEFs express mutant $p 53$ or $B u b 1$, suggesting that loss of these checkpoints may make a significant contribution to neoplastic transformation. That both genes are mutated in lymphoma suggests that their loss may be synergistic for transformation. For example, $p 53$ mutation may be required to overcome apoptosis that normally ensues when cells defective in spindle assembly checkpoint control by Bubl enter mitosis. In addition to their role in reversing growth arrest, mutations in checkpoint control may allow the accrual of chromosomal instability.

Although p53 mutation is frequent in both the model described here and in inherited breast cancer in humans with Brca2mutations, it is not universal. The studies suggest that spindle assembly checkpoint control genes may also contribute to hereditary breast cancer.

\section{References}

1. Lee H, Trainer AH, Friedman LS, Thistlethwaite FC, Evans MJ, Ponder BAJ, Venkitaraman AR: Mitotic checkpoint inactivation fosters transformation in cells lacking the breast cancer susceptibility gene, Brca2. Mol Cell. 1999, 4: 1-10. 